\title{
An investigation of Crater Diameter on Plain Slab Foamed Concrete Rice Husk Ash (FCRHA) Exposed to Low Impact Loading
}

\author{
Josef Hadipramana ${ }^{1, *}$, Abdul Aziz Abdul Samad ${ }^{1}$, Shahrul Niza Mokhatar ${ }^{1}$, Fetra Venny \\ Riza $^{1}$, Noridah Mohamad ${ }^{1}$ and Mohd Yusuf Mohd Wahab ${ }^{1}$ \\ ${ }^{1}$ Jamilus Research Centre, Faculty Civil and Environmental Engineering Universiti Tun Hussein Onn \\ Malaysia, 86400 Parit Raja, Johor, Malaysia
}

\begin{abstract}
As sustainable material building and construction, the foamed concrete (FC) in this investigation was modified by adding the Rice Husk Ash (RHA) as sand replacement to increase its strength. Furthermore, this modification material (is called FCRHA) treated on impact loading. This investigation was motivated when the plain slab of FCRHA subjected to small impactor, then the nose impactor over all would penetrate into slab target due to porosity of FCRHA. The experimental produced plain slabs FCRHA and FC (as a control) with $1400 \mathrm{~kg} / \mathrm{m}^{3}$ and $1600 \mathrm{Kg} / \mathrm{m}^{3}$ of densities. In impact test all plain slabs exposed by $40 \mathrm{~mm}$ steel blunt nose impactor with various impact velocities. The result showed the crater which produced by impact loading was not found spalling, scabbing, radial crack and widely cratering. This local damage occurred when porosity of FCRHA took over the impact loading. The nose impactor over all considered have been successful penetrated into slab of FCRHA and FC. Therefore, the diameter of crater equals to diameter of impactor. With this certainty, the prediction penetration depth on plain slab FCRHA (also FC) can be determined in future investigation. In addition, the penetration of impactor on FCRHA with low impact velocity give the same impression on penetration impactor with high impact velocity on FC.
\end{abstract}

\section{Introduction}

The application of sustainable material is not sufficient by only using lightweight aerated Foamed Concrete (FC) as construction and building material, yet the used of waste resources becoming popular ideas to reach the expected materials. Since the used of waste materials is cost effective, especially in construction industry. At the same time, the investigation on using of waste Rice Husk Ash (RHA) as construction materials is not something new [1-3] RHA in FC mixes can enhance the strength of FC [4, 5]. RHA increased the stress wall porosity in FC, and along with the increased stress, so as strain in wall porosity, which resulted in FC with RHA (FCRHA) increasing strength [6, 7]. Other than that, the FCRHA gives better impact energy absorption $[6,8]$. The RHA act as

*Corresponding author: josef@uthm.edu.my 
strengthtener in FC and increase the elasticity of FCRHA, resulting in decreased falling fragment and spalling [9]. When FCRHA exposed to impact loading then, FCRHA is able to spread the impact energy to all slab body and the porosity in FCRHA take over those loading, wherein the impact energy wave changed to tensile or compressive energy (depend on the constraint placed on a slab) taken over by porosity [10].

The basic idea of this investigation presents, that slab of FC or FCRHA decreased the local damage (crater) as wide as touching area of impactor on slab surface, when the slab subjected to impact loading. This local damage occurs, when the porosity of slab takes over the impact energy and prevent widely damage such as radial crack, wide crater, spalling or scabbing [8,9]. Meanwhile, the scabbing, spalling, widely cratering, or radial crack would be created on the rigid concrete, when it is subjected to impact loading [11].

However, previous research [8, 12] observed the crater as local damage on FC and FCRHA by using impactor with large diameter, and the result showed the blunt nose shape not fully penetrated to FC and FCRHA. The penetration depth of FCRHA has more shallow crater than FC due to different strength. This indicates that the local damage and the penetration on FC and FCRHA influenced by the role of impact velocity, target strength, nose shape and size of impactor diameter [13]. Therefore, the local damage in those case could not set at broad of nose shape impactor.

Hence, this investigation offered tracing of local damage in FCRHA should be tested by smaller impactor to prove that local damage trace on FCRHA appeared only as wide as impactor diameter even though exposed by low impact velocity as in high impact velocity on FC [9]. Thereby, the relation between nose shape impactor diameters with impact diameter can be determined.

This investigation provided the plain slabs FC (as a control) and FCRHA with densities $1400 \mathrm{~kg} / \mathrm{m}^{2}$ and $1600 \mathrm{~kg} / \mathrm{m}^{2}$. Those slabs exposed to blunt nose impactor with various low impact velocities. The most important thing in this investigation is create the relation between penetrations of impactor in FCRHA with the area of penetration of impactor on slabs, besides the local damage behaviour observation.

\section{Material and experiment}

\subsection{Material and mix proportion}

The RHA obtained from rice manufacture at Muar-Johor Malaysia which un-controlled burning under $700^{\circ} \mathrm{C}$ during \pm 6 hours. The RHA inserted into a mixture concrete to substitute the partly of sand. Where $25 \%$ volume of sand replaced by RHA on cement-sand ratios 1:4 by weight. Basically, FCRHA admixture was produced same way as FC, which this experimental, the pre-foaming method was applied. The OPC, sand, water, and RHA mixed evenly as base mixture, further added by stable preformed aqueous foam which made separately. The stable foam was created by 1:20 of foam agent-water ratio.

The base mix of FC and FCRHA produced by 3:5 of water-cement ratio. While, to avoid the absorption of water by RHA in FCRHA, then the water added into a mixture about 1.25 of RHA/water ratio. Finally, the slab target were produced by size of $300 \mathrm{~mm} x$ $300 \mathrm{~mm}$ with $200 \mathrm{~mm}$ of thickness, where the slabs target have densities about $1400 \mathrm{~kg} / \mathrm{m}^{3}$ and $1600 \mathrm{~kg} / \mathrm{m}^{3}$ that were cured for 28 days.

\subsection{Experiment}

The primary objective of this experiment was to observe the local damage behavior especially relation between the diameter of impactor and the crater on plain slab surface of 
FCRHA that created through low impact velocity. The steel blunt nose impactor (see Figure 1c) with $17 \mathrm{~kg}$ of weight and 40mm diameter (d) was used through drop weight impact method [14-16]. This method was applied where, the impactor dropped at various altitudes of $1.2 \mathrm{~m}, 1.4 \mathrm{~m}$ and $1.6 \mathrm{~m}$ which equal to $4.8 \mathrm{~m} / \mathrm{s}, 5.2 \mathrm{~m} / \mathrm{s}$ and $5.6 \mathrm{~m} / \mathrm{s}$ respectively. A pipe used to guide the fall of impactor (Fig. 1a) that falling perpendicularly on a target. During impact test, the slab target constrained on all sides including up and bottom sides (Fig. 1b) to create the magnitude compressive stress from reflected energy wave [10]. So, the plastic deformation would be expected occurs at constraint area firstly and local damage would be increased. Visually, local damage on surface plain slab was observed for diameter and penetration of impactor.
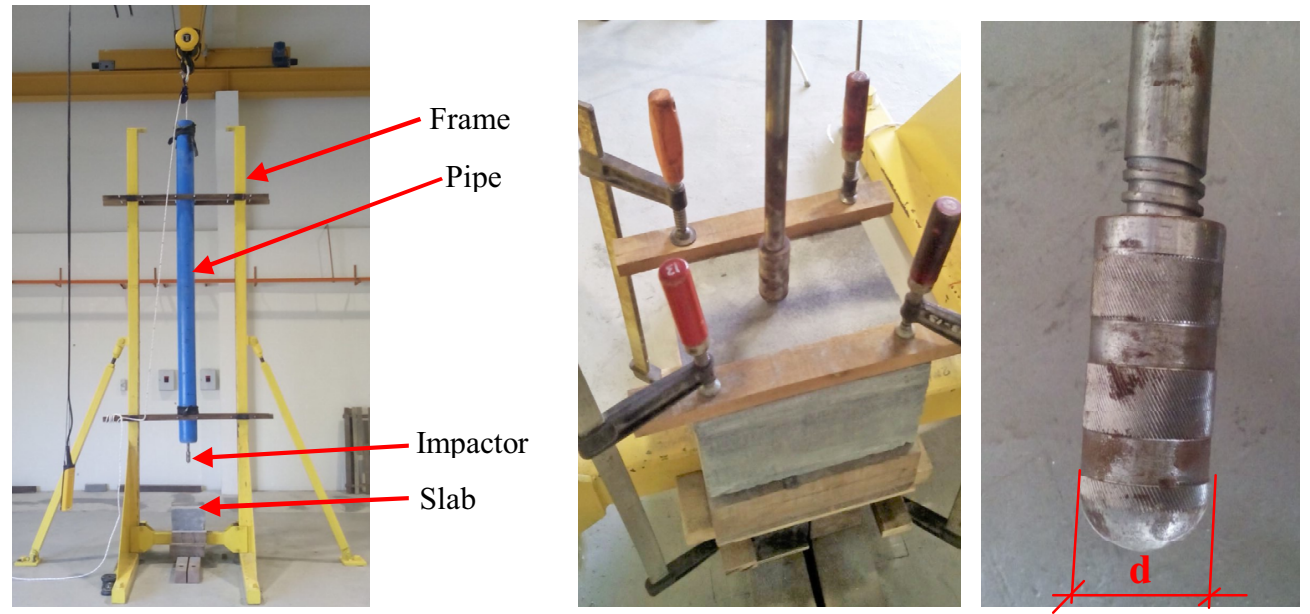

Fig. 1. (a) Drop weight impact frame (b) Slab constrained during test (c) Blunt nose shape of steel impactor

\section{Result and discussion}

\subsection{Local damage behaviour}

Local impact occurred in this investigation was crater without radial crack, spalling, scabbing nor wide cratering $[11,17,18]$ on FC and FCRHA slab target (see Fig. 2). Since the porosity of FC and FCRHA carried out the impact loading [8]. This impact loading had been transformed to be energy wave, when the impactor initial touched on surface slab target and spread in slab target transversely and longitudinally [10]. In this investigation, all sides of slab target were constrained during impact test. The energy impact that propagate in slab longitudinally is compressive stress wave and it would be enhanced to be double due to no displacement is allowed at side edge (constrained). Furthermore, the increasing stress compressive wave create a plastic compressive wave. Thus, the energy dissipation of plastic compressive wave and plastic deformation should be occurred in constrained area [10]. So that why, in this case usually the constrained area of slab could be failed firstly due to high compression energy wave that generated from impact loading. However, in this experiment the failure of constrained area was not occur to slab target FC and FCRHA (see Fig. 2), since porosity in FC and FCRHA hinder well the compression energy wave [8, 19]. 


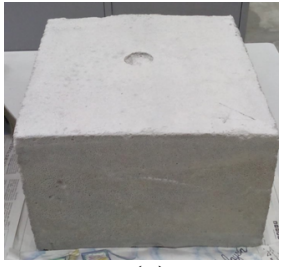

(a)

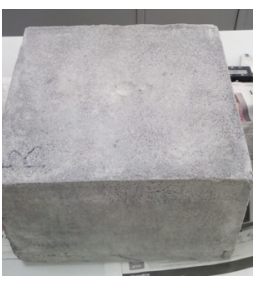

(b)

Fig. 2. The local damage as crater on slab surface of a) FC similar with b) FCRHA

Physically, there is difference between FC and FCRHA, FC is seen more porous, while the FCRHA visibly is denser (see Fig. 3). Fig. 3b shows the RHA filled up the porous of FCRHA furthermore, this is caused the FCRHA more strength than FC (see Table 1) [7]. Besides the RHA improved elasticity of porosity in FCRHA [8]. However, this physical condition does not make FCRHA different from RHA when it subjected to impact loading. The crater which created on surface of FCRHA was similar with FC. This indicates that FCRHA was good absorb energy and presence the RHA was not reduce ability absorb energy of FCRHA.

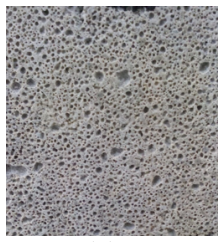

(a)

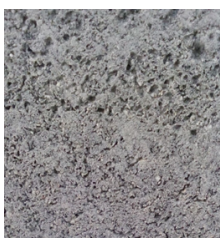

(b)

Fig. 3. Appearance of porosity on a) FC and b) FCRHA.

Fig. 4 shows the craters of slab surface of FC (Fig. 4a, 4b and 4c) and FCRHA (Fig. 4d, $4 \mathrm{e}$ and $4 \mathrm{f}$ ) with target density $1400 \mathrm{Kg} / \mathrm{m}^{3}$. Those slab target generated by impactor with different impact velocities about $4.8 \mathrm{~m} / \mathrm{s}$ (Fig. $4 \mathrm{a}$ and $4 \mathrm{~d}$ ), $5.2 \mathrm{~m} / \mathrm{s}$ (Fig. $4 \mathrm{~b}$ and $4 \mathrm{e}$ ) and 5.6 $\mathrm{m} / \mathrm{s}$ (Fig. 4c and $4 \mathrm{f}$ ). All craters clearly show that no radial crack, spalling, or widely cratering created. Nonetheless, the crater of FC for all impact velocities formed the crack on crater beyond, meanwhile the beyond crack on FCRHA visibly vague. This indicates that the elasticity of porosity of FCRHA increased $[8,19]$.

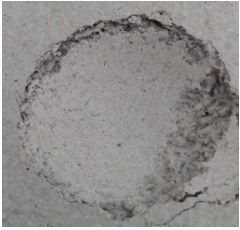

(a)

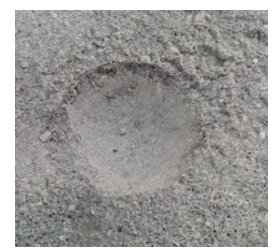

(d)

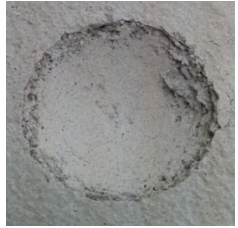

(b)

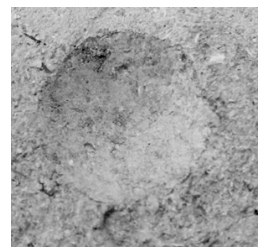

(e)

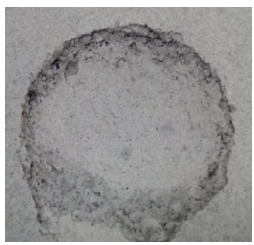

(c)

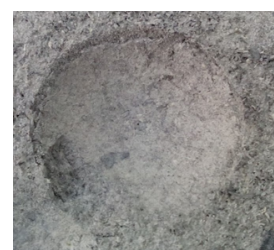

(f)

Fig. 4. The craters that formed by blunt nose impactor with various impact velocities on slab target of FC ( $a, b$ and $c)$ and FCRHA (d, e and f). All slab target with $1400 \mathrm{~kg} / \mathrm{m}^{3}$ of density 
The comparison between slab target of FC and RHA with $1600 \mathrm{~kg} / \mathrm{m}^{3}$ of density was presented in Fig. 5. Fig. 5a, 5b, and 5c show the crater of FC surfaces slab which created by $4.8 \mathrm{~m} / \mathrm{s}, 5.2 \mathrm{~m} / \mathrm{s}$, and $5.6 \mathrm{~m} / \mathrm{s}$ impact velocities, respectively. So that with Fig. $5 \mathrm{~d}, 5 \mathrm{e}$ and $5 \mathrm{f}$ for FCRHA which were exposed by the same impact velocities as FC, respectively. The result shows no different with $1400 \mathrm{~kg} / \mathrm{m}^{3}$ density of slabs target.

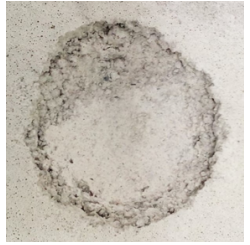

(a)

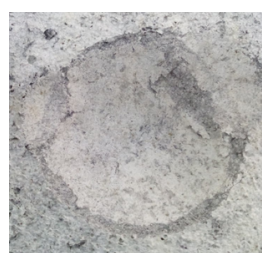

(d)

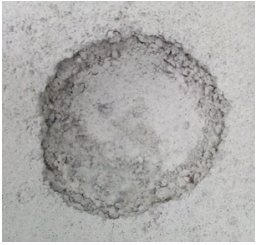

(b)

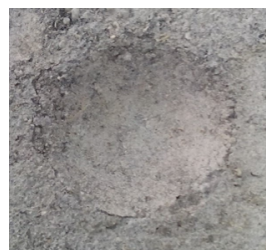

(e)

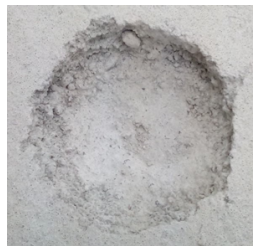

(c)

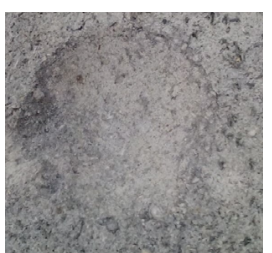

(f)

Fig. 5. Comparison of local damage on FC ( $a, b$ and $c$ ) and FCRHA (d, e and f) slab target with 1600 $\mathrm{kg} / \mathrm{m}^{3}$ of density. The local damage created the crater by blunt nose impactor with various velocities

\subsection{Penetration values}

Basically, penetration depth is essential variable for measuring the localized damage on slab concrete due to impact loading. By the penetration depth the local damage on slab could be determined, even for perforation prediction [20]. Table 1 presents the penetration depth $(X e)$ and diameter of crater $\left(D_{C}\right)$ of each material due to various velocities of impact loading.

The result shows that penetration of FC with $1400 \mathrm{~kg} / \mathrm{m}^{3}$ density was deepest than others. Meanwhile, the diameter of crater which created by impactor shows the impact velocity of $5.6 \mathrm{~m} / \mathrm{s}$ hit the FC 1400 created the largest crater than others, i.e. $40.7 \mathrm{~mm}$. Actually, the diameter of impactor was $40 \mathrm{~mm}$, it means the nose impactor wholly was success penetrate in slab concrete without cracking, spalling and widely cratering.

Table. 1. Impact test result on FC and FCRHA

\begin{tabular}{|c|c|c|c|c|}
\hline $\begin{array}{c}\text { Material } \\
\text { (density) } \\
\left(\mathrm{kg} / \mathrm{m}^{3}\right)\end{array}$ & $\begin{array}{c}\text { Compressive } \\
\text { strength }\left(f_{\mathrm{C}}\right) \\
(\mathrm{MPa})\end{array}$ & $\begin{array}{c}\text { Impact } \\
\text { velocity }(\mathrm{v}) \\
(\mathrm{m} / \mathrm{s}) \\
\end{array}$ & $\begin{array}{c}\text { Penetration } \\
\text { depth (Xe) } \\
(\mathrm{mm})\end{array}$ & $\begin{array}{c}\text { Diameter of } \\
\text { crater (Dc) } \\
(\mathrm{mm})\end{array}$ \\
\hline \multirow{3}{*}{$\begin{array}{c}\text { FC } \\
(1400)\end{array}$} & \multirow{3}{*}{3.65} & 4.8 & 11.2 & 36.7 \\
\hline & & 5.2 & 12.2 & 38.7 \\
\hline & & 5.6 & 14.1 & 40.7 \\
\hline \multirow{3}{*}{$\begin{array}{c}\mathrm{FC} \\
(1600)\end{array}$} & \multirow{3}{*}{4.5} & 4.8 & 7.4 & 30.8 \\
\hline & & 5.2 & 8.1 & 31.7 \\
\hline & & 5.6 & 9.3 & 34.1 \\
\hline \multirow{3}{*}{$\begin{array}{c}\text { FCRHA } \\
(1400)\end{array}$} & \multirow{3}{*}{3.57} & 4.8 & 7.8 & 36.3 \\
\hline & & 5.2 & 8.1 & 32.1 \\
\hline & & 5.6 & 8.2 & 32.7 \\
\hline \multirow{3}{*}{$\begin{array}{c}\text { FCRHA } \\
(1600)\end{array}$} & \multirow{3}{*}{6.62} & 4.8 & 6.1 & 28.8 \\
\hline & & 5.2 & 6.1 & 29.0 \\
\hline & & 5.6 & 6.4 & 29.0 \\
\hline
\end{tabular}


Relation between penetration depth and impact velocity presents in Fig. 6 and 7. The penetration was not significant for both material FC1400 and FCRHA1400 (see Fig. 6). In the other hand, both materials with $1600 \mathrm{~kg} / \mathrm{m}^{3}$ density, resulted the different penetration depth (see Fig. 7), where both of materials have different compressive strength (see Table 1). From the result indicates that strength of concrete play an important role for penetration depth of concrete beside impact velocity, where the result agrees with previous researchers $[13,17,20-22]$.

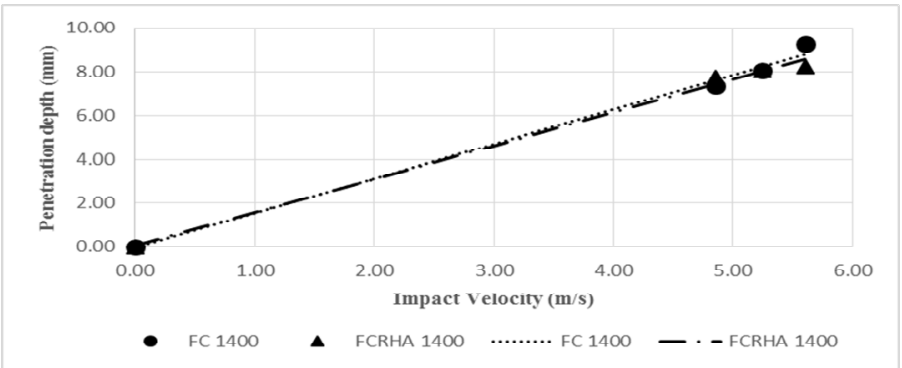

Fig. 6. Penetration depth of impactor on slab of FC and FCRHA with density $1400 \mathrm{~kg} / \mathrm{m}^{3}$

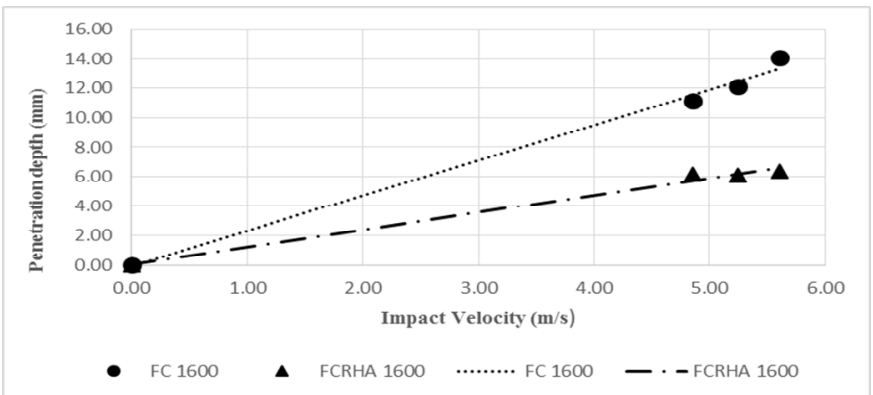

Fig. 7. Penetration depth of impactor on slab of FC and FCRHA with density $1600 \mathrm{~kg} / \mathrm{m}^{3}$

\subsection{Diameter of penetration}

In the case where the slab concrete could absorbed energy impact without radial crack, spalling, scabbing, nor widely cratering, the diameter crater is important to measure the local damage on slab target. By using different impact velocities on each material target, the result obtained relation between the diameters of the crater on a slab with penetration impactor as whichever seen in Fig. 8. The data trend line created by diameter against penetration is polynomial that will eventually constant at a certain point i.e. the diameter of impactor as seen in curve of FC1400. Meanwhile, other data inclined to follow FC1400, but not reach the value of the impactor diameter. Perhaps it caused by a deficiency of impact energy or the concrete strength was greater than FC1400, which hindering the penetration of impactor [13, 18, 21]. Although, the values of diameter crater each data are different, all penetration of whole nose impactor considered have been successful to penetrate slab of FC and FCRHA. This diameter result gives a contribution for penetration depth prediction of FCRHA and FC by the reason that the crater diameter of FC and FCRHA slab equals to a nose diameter of impactor. Therefore, the result provides the conclusion that penetration of impactor on FCRHA with low impact velocity give the same impression on penetration impactor with high impact velocity on FC [9]. 


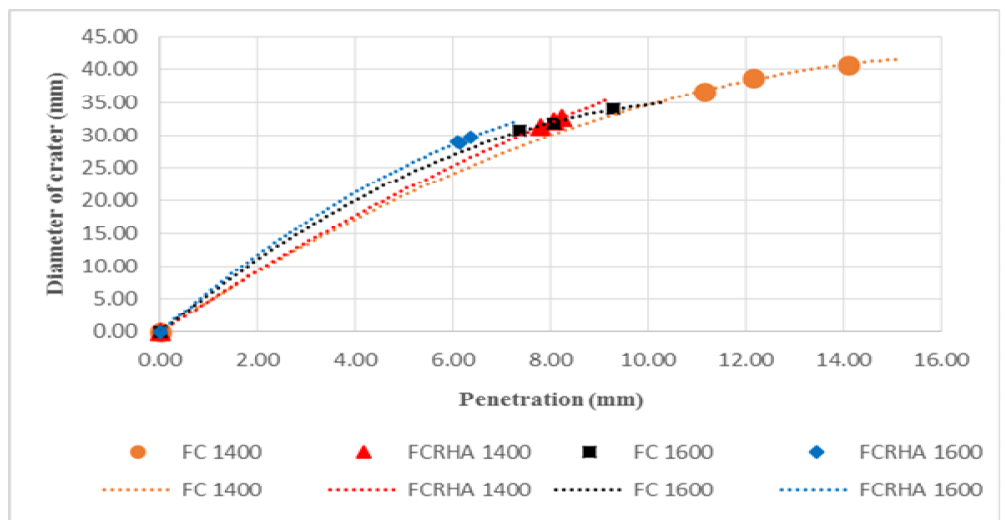

Fig. 8. Diamter of crater for FC and FCRHA with $1400 \mathrm{~kg} / \mathrm{m}^{3}$ and $1600 \mathrm{~kg} / \mathrm{m}^{3}$ due to various impact loading. The diameter crater tending toward a point the diameter of impactor

\section{Conclusion}

The investigation of diameter crater as local damage on plain slab FC and FCRHA with $1400 \mathrm{~kg} / \mathrm{m}^{3}$ and $1600 \mathrm{~kg} / \mathrm{m}^{3}$ subjected to $4.8 \mathrm{~m} / \mathrm{s}, 5.2 \mathrm{~m} / \mathrm{s}$ and $5.6 \mathrm{~m} / \mathrm{s}$ impact velocities has been conducted. The local damage produced crater with no spalling, scabbing radial crack nor widely cratering due to the porosity took over the impact load. The presence of RHA in FCRHA enhanced the wall elasticity of porous, causes the strength of FCRHA increased. The strength of concrete is play important role on penetration beside the impact velocity. So that, penetration of impactor on FCRHA more shallow than FC and cracking in crater beyond seen vague. The objectives of this investigation has been achieved that nose impactor wholly penetrated in plain slab of FCRHA, which its diameter of crater will be used as an orientation on penetration depth prediction and dimension of impact calculation in future investigation.

The authors would like to acknowledge financial and facilities support provided by University Tun Hussein Onn Malaysia under Research Supporting Grant Scheme RSGS Code U100.

\section{References}

[1] F.V. Riza, Application of RHA's pozzolanic properties in the making of CEB. Int. J. of Sustainable Construction Engineering and Technology, 2(2), 32-36 (2011)

[2] S. Singh and D. Kumar, Alternate and low cost construction material: Rice husk ash (RHA). Int. J. of Innovative Research in Advanced Engineering, 1(6), 214-217 (2014)

[3] M.S. Bhusari, Industrial application of rice husk ash (RHA) as a insulating material: A solution for reduction in land pollution, Int J Adv Engg Tech, VII(I), 552-553 (2016)

[4] J. Hadipramana, A.A. . Samad, A.M.A, Zaidi, N. Mohammad and F.V. Riza, Effect of uncontrolled burning rice husk ash in foamed concrete, Advanced Materials Research, 626, 769-775 (2013)

[5] M.H. Zhang, R. Lastra, V.M. Malhotra, Rice-husk ash paste and concrete: Some aspects of hydration and the microstructure of the interfacial zone between the aggregate and paste, Cement and Concrete Research, 26(6), 963-977 (1996)

[6] A.M.A. Zaidi, J. Hadipramana, A.A.A. Samad, N. Mohamad and F. V. Riza, Potential of RHA in foamed concrete subjected to dynamic impact loading, Key Engineering Materials, 594-595, 395-400 (2013) 
[7] J. Hadipramana, A.A.A. Samad, A.M.A. Zaidi, N. Mohamad and F.V. Riza, Contribution of RHA granules as filler to improve the impact resistance of foamed concrete. Key Engineering Materials, 594-595, 93-97 (2013)

[8] J. Hadipramana, A.A.A. Samad, R. Ibrahim, N. Mohamad, and F. Venny Riza, The energy absorption of modified foamed concrete with rice husk ash subjected to impact loading, ARPN Journal of Engineering and Applied Sciences, 11(12), 7437-7442 (2015)

[9] A.Z.A. Mujahid and Q. M. Li, investigation on penetrating resistance of foamed concrete, Structure and Building, 162, 77-85 (2009)

[10] G. Lu and T. Yu, Energy absorption of structures and materials, Abington Cambridge, England: Woodhead Publishing Limited, 50-51 (2003)

[11]G. Hughes, Hard missile impact on reinforced concrete, Nuclear Engineering and Design, 77(1), 23-35 (1984)

[12]J. Hadipramana, A.A.A. Samad, N. Mohamad, S.N. Mokhatar and F.V. Riza, Penetration depth study from previous empirical formula of modified foamed concrete slab underlow impact load from a non-deformable impactor, Jurnal Teknologi, 78(5), 147-151 (2016)

[13]Q.M. Li, S.R. Reid, H.M. Wen and A. R. Telford, Local impact effects of hard missiles on concrete targets, Int. J. of Impact Engineering, 32(1-4), 224-284 (2005)

[14]T. Ando, N. Kishi, H. Mikami and K.G. Matsuoka, Weight falling impact tests on shear-failure type RC beams without stirrups, Structures Under Shock and Impact, VI, 579-587 (2000)

[15]K. Toyota, K. Okubo, T. Fujii, T. Oguri and T. Uenoya, Mechanical properties of plain-woven CFRP reinforced by spread fiber tow during and after drop-weight impact, Structures Under Shock and Impact, IX, 455-463 (2006)

[16] M.R. Jones and L. Zheng, Energy absorption of foamed concrete from low-velocity impact, ICE Publishing, 65(4), 209-219 (2012)

[17]M.H. Zhang, V.P. W. Shim, G. Lu and C.W. Chew, Resistance of high-strength concrete to projectile impact, Int. J. of Impact Engineering, 31(7), 825-841 (2005)

[18] M. Beppu, K. Miwa, M. Itoh, M. Katayama and T. Ohno, Damage evaluation of concrete plates by high-velocity impact, Int. J. of Impact Engineering, 35(12), 1419$1426(2008)$

[19]L.J. Gibson and M.F. Ashby, Cellular Solids structure and properties (second ed.): Cambridge University Press, 175-187 (1997)

[20]Q.M. Li, S.R. Reid and A. M. Ahmad Zaidi, Critical impact energies for scabbing and perforation of concrete target, Nuclear Engineering and Design, 236(11), 1140-1148 (2006)

[21]D.Z. Yankelevsky, Local response of concrete slabs to low velocity missile impact, Int. J. of Impact Engineering, 19(4), 331-343 (1997)

[22]Q.M. Li and X.W. Chen, Dimensionless formulae for penetration depth of concrete target impacted by a non-deformable projectile, Int. J. of Impact Engineering, 28(1), 93-116 (2003) 